\title{
The Introductory Concept of Maritime Safety Audit as a tool for Identifying Potential Hazards
}

\author{
Ik-Soon Cho**In-Chul Kim*** +Yun-Sok Lee \\ * Maritime Safety Research Center, Korea Ship Safety Technology Authority, Incheon, 406-840, Korea \\ ** Maritime Safety Bureau, Ministry of Land, Transport and Maritime Affairs, Gwacheon, 427-712, Korea \\ + Sea Training Center, Korea Maritime University, Busan, 606-791, Korea
}

\begin{abstract}
Recently, the navigation risk is increasing significantly with growing of vessels' volume and propelling marine facilities, water bridges and port development etc. As a result, Ministry of Land, Transport and Maritime Affairs enacted a new law called MSA(Maritime Safety Audit) as a comprehensive maritime traffic safety management scheme in order to ensure safety improvements from the early planning stage to post managing of the development which affect the maritime traffic environment. MSA as a tool for improving maritime traffic safety is a formal safety diagnosis assessment in the existing or future ship's fairway by an independent audit institute. It examines the potential hazards of maritime traffic safety about the port development, if necessary, and is to ensure the implementation of appropriate safety measures. The primary purpose of MSA is to identify potential risk elements affecting safe navigation. This paper is aimed to introduce the backgrounds, the necessity and efficiency of MSA and also to describe some technical standards and diagnostic procedures.
\end{abstract}

Key words : Maritime Safety Audit, Maritime traffic safety, Potential safety hazards, Safety measures

\section{Introduction}

In recent days, the degree of navigational risk is increasing significantly with growing of vessels' volume and variety of marine facilities, bridges crossing waterways and port development etc. Especially, the construction of bridges crossing navigable waterways is being promoted aiming at expanding social infrastructure and optimizing the overland routes through private investment. The construction, however, tends to focus more on the commercial requirements rather than on the maritime traffic safety, which cause big risks not only ensuring the safety of ship traffic, but also in causing some severe conflicts between the parties concerned(Lee et al., 2009).

The Incheon Bridge is a newly-constructed bridge in October 2009 and amongst the five longest bridges of its kind in the world. There are differences in opinions concerning main span length within government departments, between the Ministry of Construction and Transportation and the Ministry of Maritime Affairs and Fisheries.

The fundamental cause is that maritime traffic users make objections to the reliability of the ship handling simulation which they carried out voluntarily without legal basis. Therefore, it continuously required an institutional framework to be a tool for formal systematic safety assessment in reducing marine incidents and plan safety measures.

At this point in time, the Ministry of Land, Transport, and Maritime Affairs amended the Korean Marine Traffic Laws enacting newly MSA(Maritime Safety Audit) rule which is to evaluate the traffic safety for all kinds of port and water facilities concerning with ship's passage. The act took effect from Nov. 28th, 2009(MLTM, 2009).

This paper is aimed to introduce the backgrounds, the necessity and efficiency of the MSA and also to describe some technical standards and diagnostic procedures.

\section{Overview of Maritime Safety Audit}

\subsection{Concept of maritime safety audit}

A maritime safety audit is a formal safety diagnosis examination in the field of existing or future maritime transportation by an independent audit team. It systematically estimates and identifies potential risk elements associated with the development plan and provide an opportunity to improve the traffic safety for development parties. Therefore, MSA's schemes are to identify potential safety hazards which may affect all mariners from the early design stage, and to suggest all possible measures to eliminate or mitigate those problems(Cho et al., 2009).

\footnotetext{
* First author, ischo@kst.or.kr 032)260-2264

** safe@korea.kr 02)2110-8613

† Corresponding author, lys@hhu.ac.kr 051)410-5098

Note) This paper was presented on the subject of "The Introductory Concept of Maritime Safety Audit as a tool for Identifying Potential Hazards" in 2010 Asia Navigation Conference proceedings(Incheon Korea, 4-6 November, 2010, pp.263-271)
} 


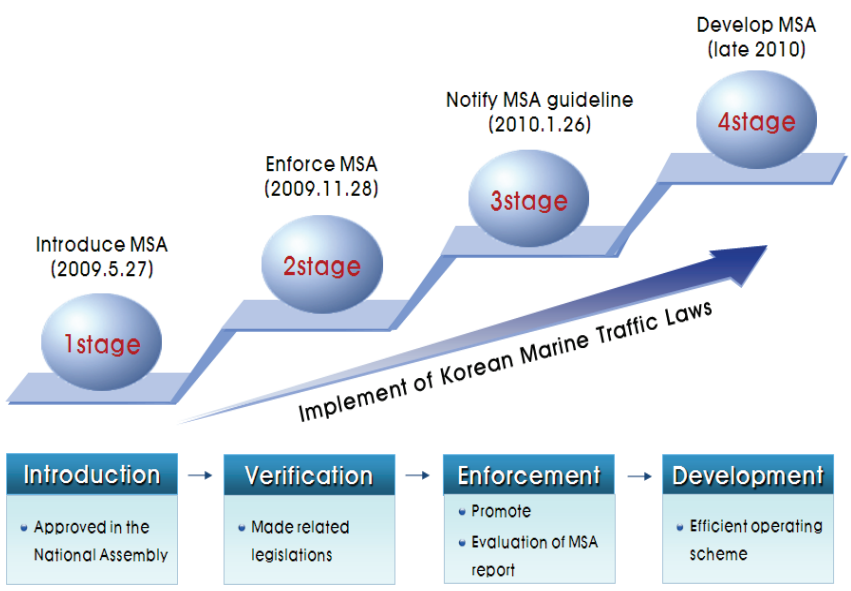

Fig. 1 Establishment procedure of MSA scheme

\subsection{Necessity of audit scheme}

The designers involved in the project for audit objects not only tried to reduce construction costs but also had to design the safety audit system, considering a number of matters including geographical conditions, environmental limits relating to the maritime traffic, the social and economical influence and budget limitation. The development parties are responsible in resolving these modern difficulties, but the maritime safety was relatively ignored and some changes were made many a time due to the principle of economical efficiency. Therefore, the audit system is required to examine all development plans for possible maritime accidents that can be reduced by taking the appropriate safety measures.

In the process of a safety assessment, the key point of audit scheme as an accident prevention mechanism is to adopt the principle of "Prevention is better than cure" during safety checking. It is because it is possible to prevent the factors threatening a safe navigation in advance in total and multi-purpose way as a part of a project for audit objects. Marine incidents can be minimized future accident occurrence and severity only if we deal with the navigational safety problems.

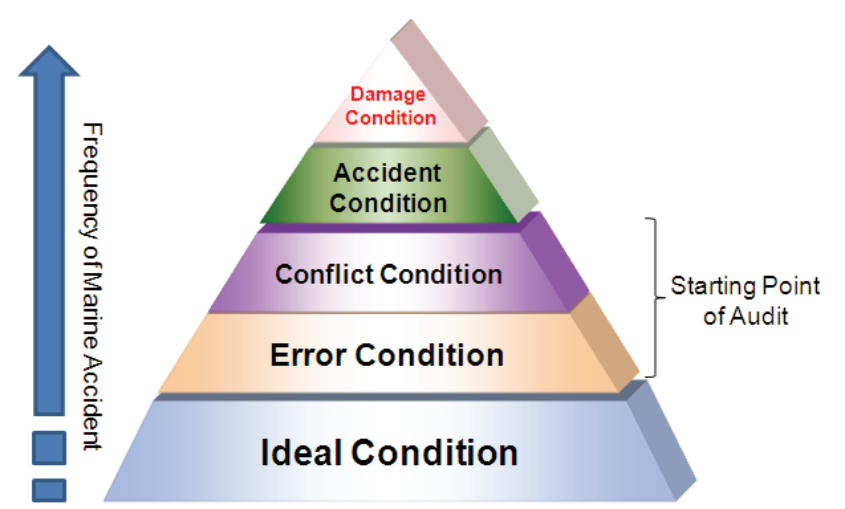

Fig. 2 Phase model of marine accident occurrences
In particular, as shown in a phase model of accident occurrences in Fig.2, the error and trouble state become a starting point and a safety audit is required from this phase. If this state lasts, it is expected that the frequency of marine incidents will rise(Durth \& Bald, 1987).

\subsection{Efficiency of audit scheme}

In general, it is known that the faster the audit is performed, the safer the results are obtained and the less costs are incurred. That is, it is more advantageous to make a compensation through a feasibility study or an audit in the basic design stage than during construction stage(U.S. Department. of Transportation, 2006).

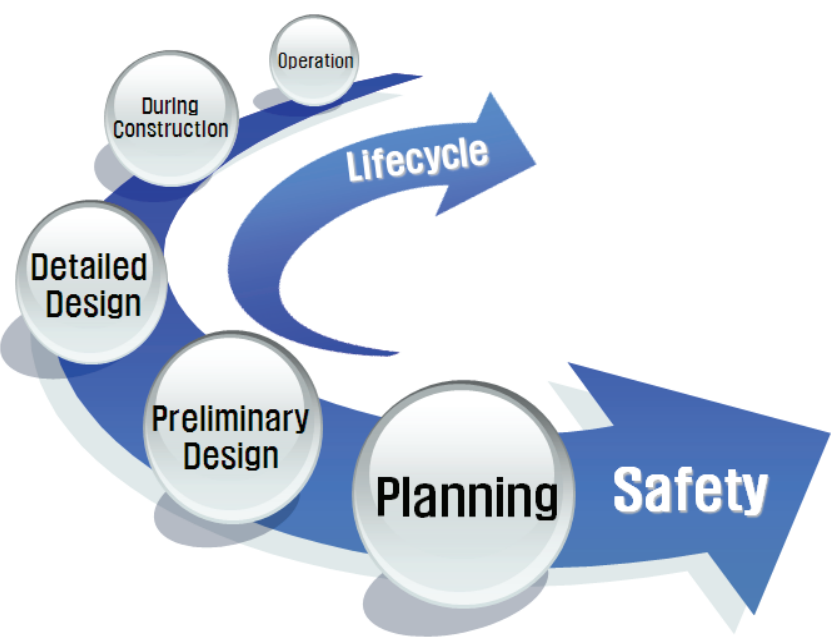

Fig. 3 Relation between project lifecycle and safety improvement

In addition, the potential benefits obtained through the implementation of an audit system are as follows.

1) The possibility of occurrence of marine incidents is reduced and the consequent savings in marine incident-related costs can be made.

2) The efficiency in a harbor is maximized due to the design considering a vessel's safety and the water availability

3) Ship's passage becomes safer

4) Designers come to pay attention to the safety of vessels

5) The possibility of additionally implemented safety measurements is reduced and the overall risk that the enforcement authority should accept is reduced

6) The design technology considering the structures in maritime field is improved

7) Economic profits are expected by blocking the factors that may cause marine incidents

It is expected to have an advantage in improving safety 
policies and project designs in an economic aspect of reducing marine incidents when the audit system is executed.

Badly designed or maintained sea routes can contribute to human error and lead to marine incidents. Conversely, well designed and maintained sea routes, where the needs of mariners have been anticipated, can reduce potential risks and result in safer sea.
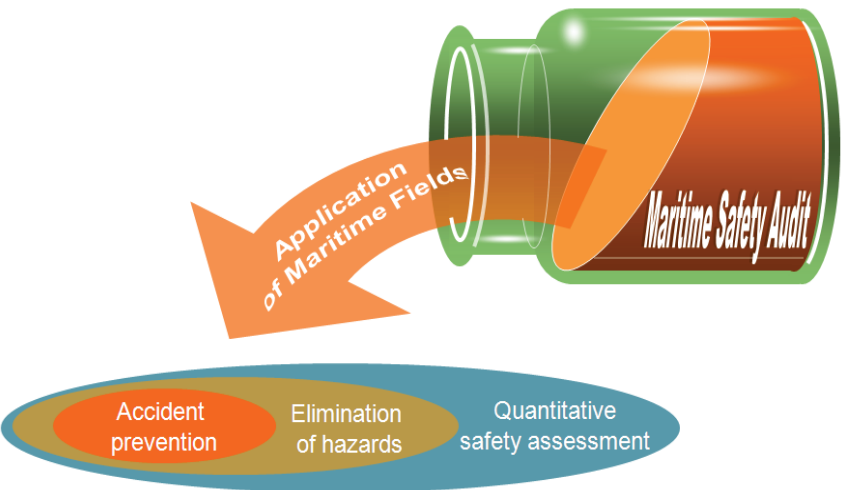

Fig. 4 Expected effect of MSA scheme

\subsection{Basic principles of audit}

To perform maritime safety audit, it is essential to establish 3 factors of 'Formalization', 'Standardization' and 'Independence' as shown in Fig.5. Formalization is an important part in the planning procedure and means the regulations that the 3rd parties like project owners, designers, and audit teams should observe. Standardization refers to the technology allowing you to make an evaluation having clear regulations on the introduction and performance of an audit and the level of the audit results. Independence means the concept on the role of an audit team performing a safety audit and an audit team doesn't take any responsibilities for any projects on audit objects and receive any order from ordering institutions or any designers.

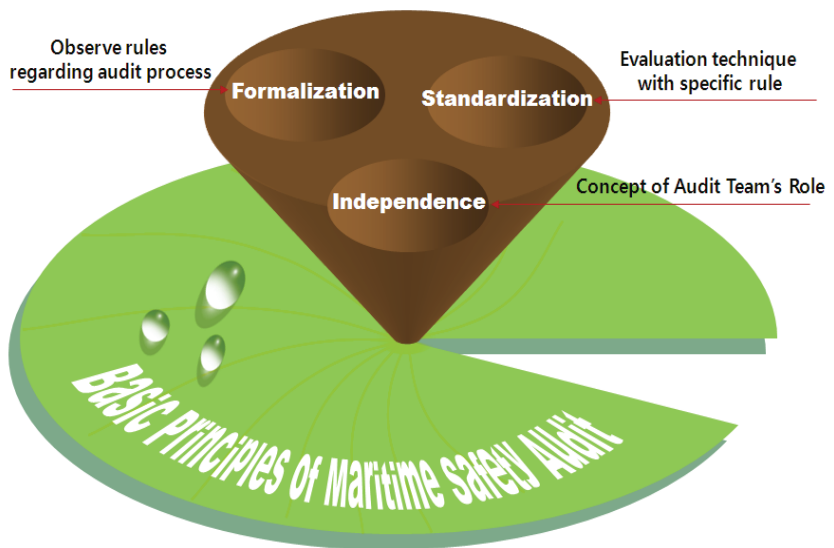

Fig. 5 Basic principles of Maritime Safety Audit
However, it is desirable to maintain a close cooperative relationship with designers to prevent errors from being made in the early stages(Korea Transportation Safety Authority, 2005).

\subsection{Scheme to be audited}

The Article 2(Definition) in the Korean Marine Traffic Laws defines a maritime safety audit as the professional investigation, measurement and evaluation of the safety hazards that may occur from projects as follow.

1) The establishment and change of water zones

2) The construction, building and repair of bridges, tunnels, and cables installed in water zones

3) The development and redevelopment of harbors and ports

4) Projects regulated by the ordinances of the Ministry of Land, Transport, Maritime Affairs as a project that remarkably affects other maritime traffic safeties.

MSA is now a mandatory requirement in all marine projects except in special circumstance like emergency construction which makes little influence on navigational safety. In this case, it is possible to submit in a simplified audit report which can exclude full-mission ship handling simulation.

\subsection{When to audit}

In the case of a maritime safety audit, specific audit timing has not been separately mentioned, so it is not clear when the audit should be performed. This is so that the audit must be performed at least more than once as a prior audit.

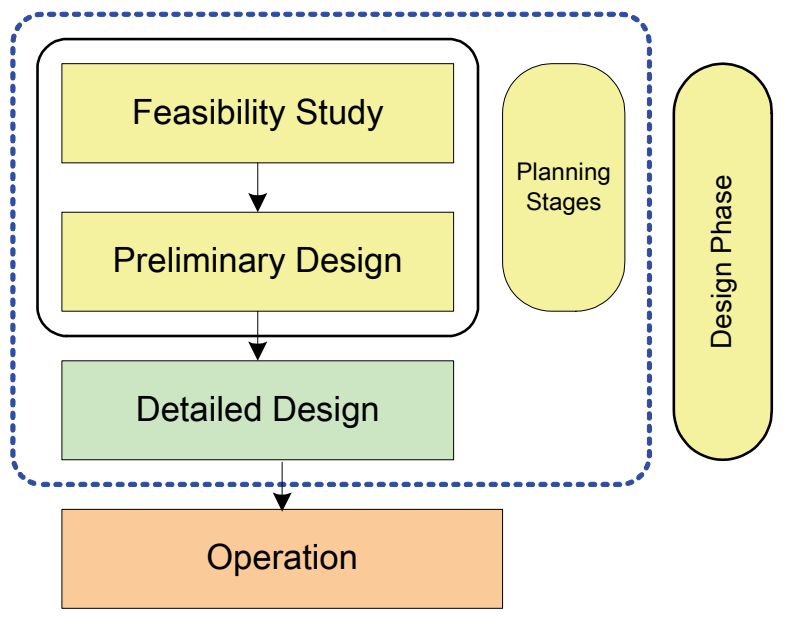

Fig. 6 Audit timing

In the case of a road, an audit is basically performed in 
design phase and in case of the section where traffic accidents frequently occur, a special road safety audit is being performed in opening and operation stages as well.

Thus, it is necessary to observe the following principles in the audit timing of maritime traffic safety.

1) Basically it is the principle to perform an audit in planning stages including a feasibility study, preliminary design as shown in Fig.6. It is because the earlier an audit is performed, the more efficient it can be in safety and cost aspects because revisions in design can be made before construction stage.

2) If a marine incident happens in operation phase because of the project for audit objects, it is possible to perform a post-construction audit like road safety audit. However, an audit of the current Korean marine traffic laws is a concept for a prior audit, so it is necessary to conduct an audit in the post-construction phase which will have a different focus from a traditional safety review or investigation of marine incidents. Namely, it is necessary to make amendments to post audit related legislations in the future.

\section{Conducting Maritime Safety Audit}

\subsection{Audit framework}

The basic audit framework in project processing includes undertaking an audit and submission of an audit report by the Law may be summarized as shown in Fig.7.

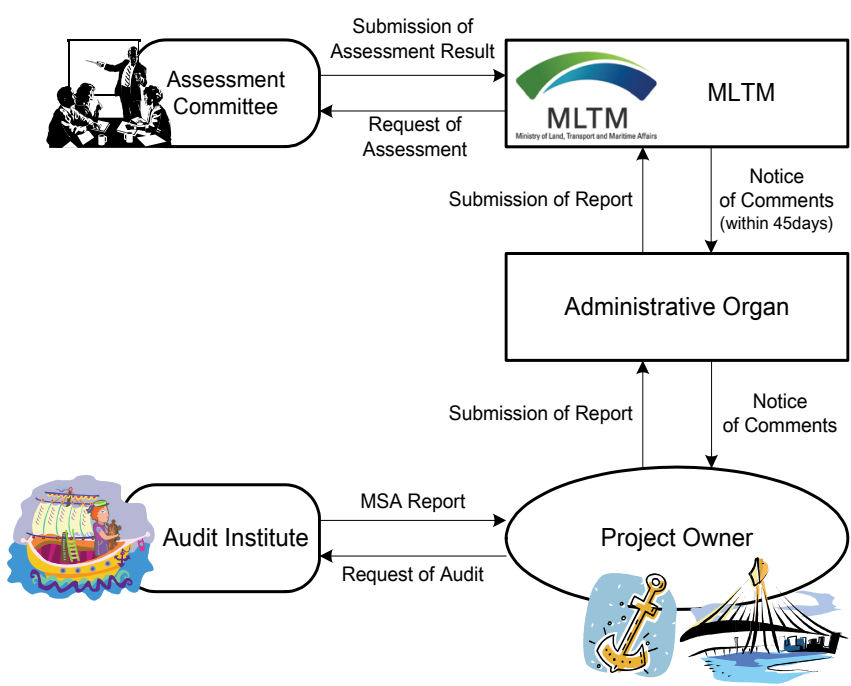

Fig. 7 Audit framework of MSA

\subsection{Audit process}

The maritime safety audit typically proceeds according to the procedures as shown in Fig.8. Some of the procedures can be omitted or simplified according to the characteristics and scale of a project, but basically, the steps for performing an audit should be observed. Also, notable fact is that kick off and final meeting with marine users must be presented in a process of auditing.

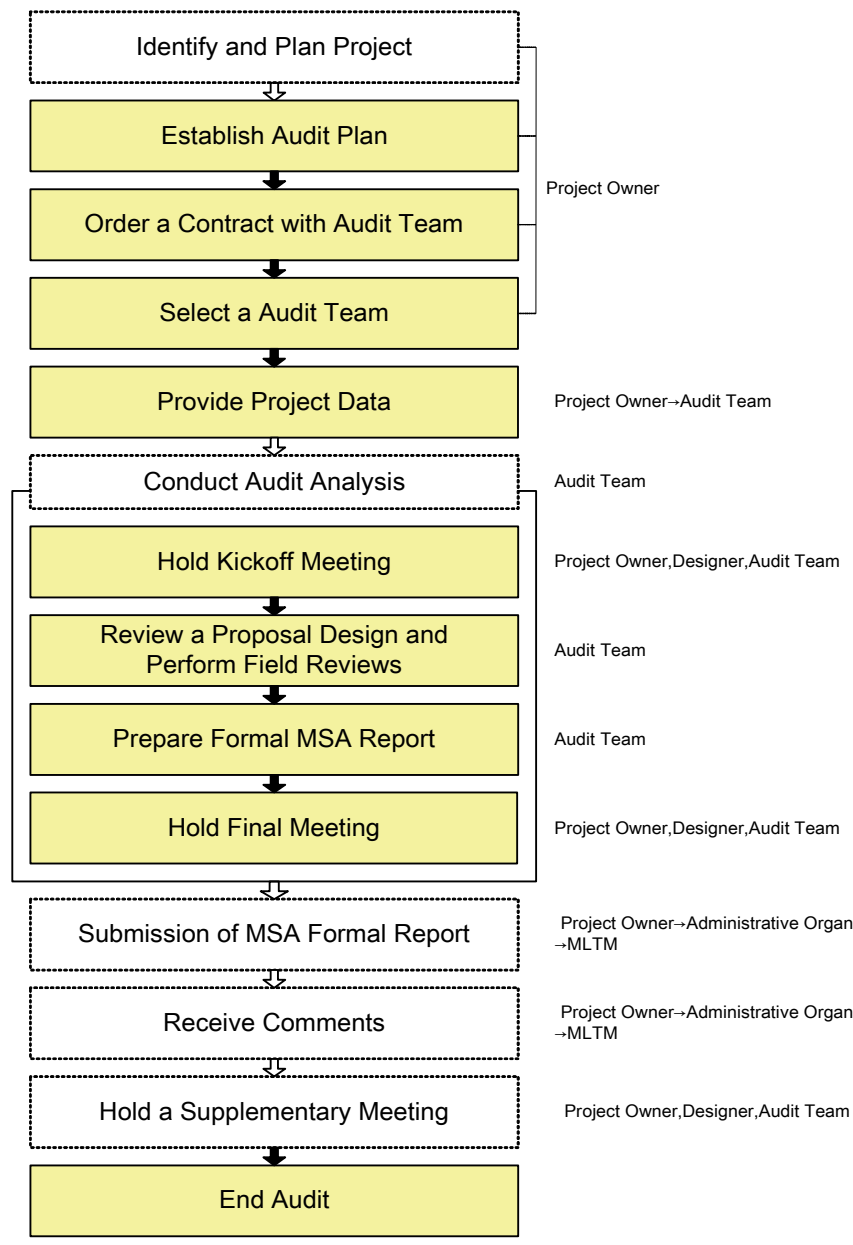

Fig. 8 Audit process

\subsection{Assessment committee}

To evaluate a submitted audit report, an assessment committee must be utilized so that it can be objective and there is no omitted item.

To professionally evaluate audit report, maritime safety audit assessment committee shall be established, composed of over 20 persons, an assessment shall be performed, and the results shall be reported to the Minister of Land, Transport, and Maritime Affairs. The evaluation results made by the committee shall be notified to the project owner with a review opinion, and in case it is judged to be a poor audit, suspensions shall be imposed..

In fact, it is difficult to form an evaluation committee for every audit object project due to a fixed budget and in aspect of committee management. Thus, the evaluation on 
audit results shall be performed under one of the following conditions.

1) In case a safety audit is not properly performed and it may result in a serious risk to maritime traffic safety,

2) In case a project for audit objects seriously affects maritime traffic safety

3) The Minister of Land, Transportation, and Maritime and the administrative organization acknowledge the fact that, judging from the results, a poor audit has been performed and require an audit team to evaluate those results

\begin{tabular}{|l|}
\hline \multicolumn{1}{|c|}{$\begin{array}{c}\text { Survey of Existing } \\
\text { Maritime Traffic State }\end{array}$} \\
\hline - Project outline \\
- Design criteria \\
- Natural environment \\
- Navigational condition survey \\
- Maritime traffic survey
\end{tabular}

\begin{tabular}{|c|}
\hline \multicolumn{1}{|c|}{$\begin{array}{c}\text { Establishment of } \\
\text { Safety Countermeasures }\end{array}$} \\
- Expert's opinion \\
- Assessment items if need be \\
alternative \\
- Countermeasures for safety \\
\hline
\end{tabular}

Fig. 9 Audit items

\subsection{Investigation items}

The essential audit items during maritime safety audit are needed for the procedures of performing the evaluation, using all kinds of evaluation technologies like a simulation technology, and establishing the safety measurements required on a basis of the evaluation results after the basic investigation on maritime traffic and the traffic states are measured.

Table 1 Performance audit items by project kinds

\begin{tabular}{|c|c|c|c|c|c|c|c|c|}
\hline \multirow{2}{*}{\multicolumn{2}{|c|}{ schemes }} & \multirow{2}{*}{$\begin{array}{l}\text { Survey } \\
\text { of } \\
\text { traffic } \\
\text { state }\end{array}$} & \multirow{2}{*}{$\begin{array}{c}\text { Measure } \\
\text { ment of } \\
\text { traffic } \\
\text { state }\end{array}$} & \multicolumn{4}{|c|}{ Adequacy Assessment } & \multirow{3}{*}{\begin{tabular}{|c} 
Safety \\
measures \\
$\mathbf{0}$
\end{tabular}} \\
\hline & & & & \multirow{2}{*}{\begin{tabular}{|c|}
$\begin{array}{c}\text { Navigati } \\
\text { onal } \\
\text { Safety }\end{array}$ \\
\end{tabular}} & \multirow{2}{*}{$\begin{array}{c}\text { Berth/ } \\
\text { Unberth }\end{array}$} & \multirow{2}{*}{$\begin{array}{c}\begin{array}{c}\text { Moori } \\
\text { ng }\end{array} \\
-\end{array}$} & \multirow{2}{*}{\begin{tabular}{|c|}
$\begin{array}{c}\text { Traffic } \\
\text { Flow }\end{array}$ \\
$\triangle$
\end{tabular}} & \\
\hline \multirow{2}{*}{$\begin{array}{l}\text { water } \\
\text { zone }\end{array}$} & $\begin{array}{c}\begin{array}{c}\text { establish- } \\
\text { ment }\end{array} \\
\end{array}$ & & & & & & & \\
\hline & change & & ○ & 0 & $\triangle$ & - & - & \\
\hline \multirow{2}{*}{$\begin{array}{c}\text { facility } \\
\text { in water } \\
\text { zone }\end{array}$} & $\begin{array}{c}\text { con- }^{-} \\
\text {struction }\end{array}$ & & & & $\triangle$ & $\triangle$ & 0 & \\
\hline & repair & ? & 0 & 0 & - & - & - & \\
\hline \multirow{2}{*}{$\begin{array}{c}\text { harbor } \\
\text { /port }\end{array}$} & development & 0 & 0 & 0 & 0 & 0 & $\triangle$ & \\
\hline & \begin{tabular}{|c|}
$\begin{array}{c}\text { redevelop- } \\
\text { ment }\end{array}$ \\
\end{tabular} & & & & 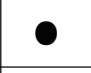 & O & - & \\
\hline \multicolumn{2}{|c|}{ regulated by MLTM } & & $?$ & 0 & $\triangle$ & $\triangle$ & $\triangle$ & \\
\hline
\end{tabular}

: mandatory, $\triangle$ : as occasion demands
The following table shows an investigation method and an evaluation method that have to be performed in detail. The vertical axis shows the projects of audit objects and the horizontal axis lists the method of the investigation and a standard method of the audit, which all should be performed for each object project, and whether or not to hold an evaluation committee. The mark "O" in the table means the performance of an evaluation method and the " $\triangle$ " the performance as occasion demands.

\subsection{Audit institute}

The objective of selecting an audit team is to choose an independent, qualified and multidisciplinary team of experts who can successfully conduct a maritime safety audit. It may be fair to say that success or failure of an MSA depends on selecting an audit team. The role of audit institute is very important in MSA schemes.

An audit institute is recommended to consist of a minimum of 8 members and required to be independent of the design team and it also should be registered by the MLTM and equipped with the facility of three dimensional full mission ship handling simulator.

Currently, there are three registered audit institutes such as Mokpo Maritime University, Maritime \& Ocean Engineering Research Institute and Korea Maritime University(as registration order).

In the case of design and building schemes, the audit team shall be from a completely separate organization to the design team.

\subsection{Prepare the audit report}

The audit report prepared by the audit team is expected to describe potential safety problems and identify the proposals to overcome or mitigate them.

The main body of the audit report will contain all of the identified safety issues, evaluation of safety risks and suggestions concluding statement signed by the audit team members indicating that they have participated in the audit and agreed consensus on its findings. Especially, all safety problems highlighted should be stated as clearly as possible.

The suggestions on audit reports should be constructive and realistic considering the costs, and should recognize that project owners may have different options to achieve the desired result.

\section{Conclusion}

Recently, vessels have significantly become larger and 
faster, but the ship's fairway is not wide enough.. Furthermore, as many projects are actively being carried out for the improvement and optimization of the maritime traffic system, the installation of marine structures and port development, the possibility of more marine incidents is probably much higher.

Dealing with the situations mentioned above, the Ministry of Land, Transport, and Maritime Affairs has enacted a maritime safety audit scheme which evaluates the safety degree of vessel navigation for developing projects before it has been approved.

In this paper, the concept of an audit, necessity and efficiency of audits were introduced stressing comprehension of an audit scheme, and MSA scheme for maritime traffic safety, to set the future direction of the transition point suggested.

The MSA scheme which has been newly introduced can be used on all types of developing projects relating to maritime traffic to reduce the risks but it can only contribute to accident prevention. It is also necessary to undertake accident reduction by identifying safety hazards and improving navigational safety as an effective proactive tool for maritime safety management system.

It seems that the maritime safety audit system is required to conduct constant researches and audit application for verifying and extending technical standards in the current initial implementation phase, and it is necessary to develop a variety of technologies and conduct the verification so that more objective and qualitative improvements in the auditing system can be made in the near future.

\section{Acknowledgements}

This research was a part of the project titled "Development of the Evaluation Model for the Maritime Traffic Safety" funded by the Ministry of Land, Transport and Maritime Affairs, Korea.

\section{References}

[1] Cho I.S., Lee S.J., Kim I.C., Hwang E.S. and Lim K.T.(2009), "Introduction to Maritime Safety Audit(MSA) and its Guidelines", 2009 Spring Conference Proceeding of the Korean Society of Marine Environment \& Safety, pp. $79 \sim 84$.

[2] Durth \& Bald(1987), Risikoanalysen im StraBensesen, Zeitschrift fur Verkehrssicherheit, pp.17 24.

[3] Korea Transportation Safety Authority(2005), Study on the Guidelines and Prerequisite for road safety audits projects of self-governing bodies

[4] Lee Y.S., Cho. I.S., Park Y.S. and Park J.S.(2009), "Construction Processing Analysis of Domestic Bridges Crossing Navigable Waterways and Improvements", Journal of the Korean Society of Marine Environment \& Safety, Vol.15, No.2, pp.119 125 .

[5] MLTM(2009), A Study on Maritime Safety Audit Guideline

[6] U.S. Department of Transportation(2006), FHWA Road Safety Audit Guidelines, pp.1 52.

Received 2 September 2010

Revised 23 November 2010

Accepted 2 December 2010 